Uniwersytet w Białymstoku

Wydział Filologiczny

Instytut Filologii Wschodniosłowiańskiej

tel.: +48857457450

e-mail:wsupa@op.pl

\title{
Сатира Юрия Полякова в контексте достижений русской классической сатиры
}

Юрий Поляков является одним из широко известных современных русских писателей, к которому критика и читатели прикрепили этикет сатирика ${ }^{1}$. Анализ произведений первого (до конца 80-х г.) и второго этапов его творчества дает возможность проследить смысловое поле, приписываемое термину «сатира» некоторыми писателями, критикой и читательской публикой. Сатирическими часть критиков считала уже ранние, обличительные произведения Полякова из-под знака «позднего соцреализма», написанные им в начале 80-х г., но опубликованные несколько лет позже в период перестройки. Автор детально освещал в них явления большинству читателей незнакомые, как армейская «дедовщина» (Сто дней до приказа, 1980, публикация 1987), кулисы рутинной деятельности районного комитета комсомола (ЧП районного масштаба, 1981, 1985), проблемы советской школы Работа над ошибками (1986), используя реалистические, с аксиологически-эмотивной точки зрения почти нейтральные приемы изображения (правдоподобие,

\footnotetext{
1 В 2013 г. Поляков получил премию им. Салтыкова-Щедрина за «ироническую» трилогию Гипсовый трубач. В ответном слове на торжестве вручения приза он подтвердил, что его учителями являются Щедрин, Гоголь и Булгаков. [Ю. Поляков, интервью А. Каскову, online].
} 
достоверность по отношению к внелитературному миру, даже «скучноватая бытовуха»).

Например, повесть ЧП районного масштаба с ее поэтикой, припоминающей структуру производственной прозы (писатель детально знакомит читателя с делами, которыми занимается районный комитет комсомола и его секретарь в частности, типа организация слетов молодежи, пропагандистских собраний в предприятиях, и т. п.), могла восприниматься и как в меру объективное изображение фрагмента советской действительности, или, в зависимости от мировоззрения реципиента, как некомическая сатира, не покушающаяся на устои системы, а лишь на наиболее явные ее пороки. Но одновременно это пример, наглядно иллюстрирующий, что в длительном процессе восприятия, когда меняются основные конгредиенты жизни (политический строй, юрисдикция, материальные условия существования, условия доступа к источникам информации), слагаемые литературных произведений сами по себе «генерируют» категорию юмора и приобретают другой смысл (иногда даже вопреки воле автора), т. е. пафосное, серьезное может превращаться в них в смешное, похвала в критику и т. п. Например, современных читателей, в т.ч. студентов русской филологии, смешат слова о безошибочности КПСС или о гениальности советских вождей, встречаемые в официальной литературе советского периода. Категорию сатиры укрепляет в таких произведениях прежде всего новая оценка недавнего прошлого, увеличивающая абсурдность того, что долгие годы считалось нормальным, или ничтожность и опасность многих тогдашних ценностей. Итак, в обсуждаемой повести в наши дни смех вызывают фрагменты, подчеркивающие преданность главного героя Шумилина делу партии, его усилия, направленные на реализацию навязанной сверху программы, штамповость и схематизм этой программы, оторванность от жизни. Деятельность районного комитета комсомола воспринимается как «искусство для искусства», т. е. как явление большинству общества совершенно ненужное и даже вредное для него. Произведение представляет собой случай, когда носителями сатиричности «второй степени» стали достоверные ${ }^{2}$ описания обстоятельств и поведения действующих лиц, реализованные при помощи слов, не наделенных непосредственно оценочным оттенком, благодаря тому, что исчезли их внелитературные, реальные соответствия, а пе-

2 Поляков знал по собственному опыту дела Комсомола, так как некоторое время был секретарем этой организации в московском отделении Союза писателей. См., напр., биографические данные [Курицын 1994, т. 1, 488-505; Румянцев, online]. 
реоценка ценностей обнажила парадоксальность. Кстати, в произведениях, показывающих недавнее прошлое с перспективы новой эпохи, вырабатывается своеобразный, аксиологически негативный, архетип советскости.

Но в творчестве Ю. Полякова вскоре появилась и «полноценная» сатира, понимаемая как высмеивание отрицательных сторон определенной действительности при помощи уже канонических приемов: гиперболизации, иронии, карикатуры, пародии, гротеска или абсурда [см. шире: Supa 2002, 16-19]. Конечно, не все из перечисленных приемов являются необходимыми для создания сатиры, достаточно хотя бы двух из них. Первым произведением интересующего нас писателя с уже заметными элементами сатиры, близкой классической, считается роман Апофегей (1989), в котором встречаем карикатурный портрет партийного руководителя, припоминающего Бориса Ельцына и деградирующие афоризмы в обобщающей функции, которые впоследствии станут «знаковыми» для Полякова-сатирика; самым удачным из них в Anофегее кажется следующий: «школьная программа по истории сказки тетушки КПСС». А начиная с повести Парижская любовь Кости Гуманкова (1991) сатирические элементы в его творчестве значительно обогащаются, в первую очередь за счет включения в повествование и прямую речь героев миниатюрных жанров: кроме афоризмов юмористически-сатирических анекдотов, шуток, острот, функционирующих в соседстве традиционных, выступающих почти в каждом сатирическом произведении слагаемых - метких снижающих определений, гипербол и карикатур.

Главный герой (одновременно повествователь) Парижской любви.., в некоторой мере porte parole реального автора, это тонкий иронист, остроумно комментирующий и условия жизни в СССР 80-х г. (бюрократизм, недостаток всего необходимого, доходящая до абсурда партийная бдительность) и двойственную мораль советского человека. Сюжет основан на приеме столкновения сознания homo sovieticus c западной действительностью ${ }^{3}$. На этот раз предметом обличения избран один из основных тезисов советской пропаганды, укоренившийся в сознании миллионов людей - превосходство всего советского над западным. Разоблачает этот миф история поездки типичной советской тургруппы в Париж, изобилующая в ряд комически-грустных сюжетных ситуаций, в которых участвуют и персонажи в общем положительные, но, в первую очередь, целый ряд идеологических демагогов и подхали-

3 Анализ этого произведения см.: [Jankowski 1998, 182-188]. 
мов, так как группа состоит из партийных руководителей, представителей творческой и технической интеллигенции, рабочего, колхозницы, генеральской жены. Все знают, что среди них есть «сексот». Гуманков даже пытается разгадать, кто это, что вносит в повествование элемент сенсации. Несмотря на тщательную идеологическую подготовку и постоянный контроль, члены группы в столкновении с реальностью «потребительского общества», т. е. с обилием товаров в парижских магазинах, пережили большее или меньшее потрясение, а впервые попавшая за границу бригадир доярок из колхоза «Красная заря» даже сильный шок. Герой-повествователь констатирует:

В супермаркете я почувствовал себя папуасом, который всю жизнь молился на свои единственные стеклянные бусы и вдруг нежданно негаданно попал в лавку, доверху набитую всевозможной бижутерией. Здесь было все, о чем только смеет мечтать советский человек, о чем он не смеет мечтать и даже то, о чем мечтать ему не приходит в голову [Поляков, Парижская любовь..., 27, online].

Таким образом в забавной форме на конкретных примерах показаны трещины в мироощущениях, которые в какой-то мере привели к слому казалось бы вечной политической системы.

Сатирическую окраску изображаемого (поведение советского человека в своей стране и за границей, карикатурные портреты гомо советикус) усиливает в повести именно каскад анекдотов, рассказываемых Гуманковым и его соседом из гостиничного номера, бывалым журналистом, оказавшимся доносчиком. Например:

- А знаешь анекдот? - оживился Спецкор - значит, мужик на Красную площадь на очередные похороны ломится. Милиционер спрашивает: «Пропуск». А мужик: «У меня абонемент».

- А знаешь другой анекдот? - подхватил я. - Очередь в железнодорожную кассу. Первый просит: «Мне билет до города Брежнева!». Кассир «пожалуйста!». Второй просит: «А мне до города Андропова!». Кассир - «пожалуйста». Третий просит: «А мне до города Черненко»! Кассир «Предварительная продажа билетов за углом» (с. 38$)$.

Анекдоты в общем приписываются «народу языкотворцу» и отражают фольклор эпохи застоя и смеховую культуру этого времени, но критики подчеркивают и «обратную связь», т. е. факт, что многочисленные языковые «изобретения» Полякова (кстати, его афоризмы уже изданы отдельно в двух томах) обогащают современный русский язык, его смеховой потенциал. Анекдоты, прежде всего политические, это по- 
пытка определить и оценить факты и явления в миниатюрном, концентрированном сюжете или комментарии с помощью приема метафорических совпадений и ассоциаций иногда далеких по смыслу понятий. Благодаря краткости и емкости способной сигнализировать глубокий смысл это очень эффектная форма передачи информации с эмотивной, в данном случае сатирической, нагрузкой.

Незадолго после публикации Парижской любви... появились два произведения Полякова, в которых сатира играет роль доминанты в конструировании их художественного мира: повесть Демгородок (1993) и роман Козленок в молоке (1995). Первое из названных выше произведений представляет собой политическую сатиру с элементами гротеска ${ }^{4}$, сатиру уже на посткоммунистический период, в первую очередь на затянувшиеся в России поиски демократических норм правления страной и организации общественной жизни и затем на возрождающийся неототалитаризм. Картина мира построена в этом произведении на фантастическом антиутопическом допущении, на синтезе избранных явлений прошлого, настоящего и экстраполяционного будущего. Главным «героем» на этот раз является вымышленный город-лагерь, место ссылки для поверженных представителей самой высокой власти - экс-президентов, их жен и сотрудников. Текст открывает эпиграф из Страшной мести Гоголя говорящий о том, что самым тяжелым грехом считается тайное предательство земли русской, и можно предполагать, что именно такое преступление совершили и бывшие, и современные представители номенклатуры, которые «разворовывали отечество». Россией правит самозванец адмирал Рык, захвативший власть после военного переворота и присвоивший себе звание «Избавителя Отечества». Как властелин он концентрируется на разоблачении «злодеяний периода Демократической смуты», «врагоугодников и отчизнопродавцев» и создании нового пропагандистского языка, дающего возможность воспевать мнимые достижения.

Конечно, портрет адмирала Рыка вмещает черты многих деспотов разных времен: и царей, с которыми он мечтает породниться через женитьбу на «Рюриковне», и Сталина, и Ельцина и современных глав тоталитарных государств, так как ему свойственно вульгарное остроумие, слабость к алкоголю, показные скромность, либерализм и демократизм, а на самом деле мечты о невероятном возвышении (поощ-

4 В работах посвященных творчеству Полякова, не до конца обоснованно, функционирует даже термин «гротесковый реализм Полякова». См.: [Поляков- Пересторонин 2005, online]. 
рение литературной «рыкияны») и экстремальная жестокость (надоевших оппозиционеров он прагматически продает Западу «на запчасти», т. е. для пересадки органов). Кроме того, в повести подчеркивается безрезультатность правительственных затей, и то при затрате огромных финансовых и человеческих ресурсов. Текст содержит многочисленные аллюзии к русской и мировой истории 80-х и начала 90-х гг., напр., к взлетам и упадкам высоких государственных чиновников, к планированным, но не проведенным реформам, конфликтам, которых можно было избежать, но также и футурологические прогнозы ${ }^{5}$. Например, на тему предполагаемых отношений России с Украиной Поляков в начале 90-х г. написал следующее:

С Украиной ... дело чуть не дошло до войны! Даже объявили частичную мобилизацию. Но тут оказалось, что министр обороны России - украинец, а министр обороны Украины - русский, российская армия на $21 \%$ состоит из украинцев, а украинская на $38 \%$ из русских. Кроме того восстал Крым и объявил себя независимым курортно-профилактическим государством, шахтеры Донбасса с месячным запасом сала и хлеба спустились в забои и объявили голодовку; наконец, в Одессе, где был запрещен русский язык, Дерибасовскую перегородили баррикадой из русско-украинских словарей и разговорников. В довершение всего украинский президент имел неприятное объяснение со своей женой - кацапкой, а Иван Петрович бурно посоветовался со своей супругой хохлушкой [Поляков, Демгородок, 39].

Писатель, между прочим, обратил внимание на «конфликтогенные» последствия совместной истории, когда на территории бывших советских республик перемешались нации и экономические интересы, но не настолько, чтобы у жителей сложились общие, мирные планы на будущее. В повести опасность братоубийственного кровопролития легко и «гениально» предотвратил Избавитель Отечества чисто вербальным путем, предложив ради «сохранения славянского единства»... переименовать «Московскую область в Залесскую Украину, а Украину и впредь считать Русью, как это и было при Рюриковичах». K сожалению, в реальной действительности все сложнее, и забавного не так уж много, а неосторожно активизированные конфликты длятся годы и десятилетия.

Кроме традиционных способов конституирования сатиры, применяемых Поляковым уже в предыдущих произведениях, таких как: сни-

5 Критик Бондаренко называет даже Полякова полушутя «литературным Нострадамусом» [Бондаренко 2001, online]. 
жающие определения, нелепые ситуации, диалоги, обнажающие пороки персонажей и изъяны политической системы, в Демгородке использованы, как уже сигнализировалось, условные формы - сплав правдоподобного с антиутопической фантастикой, образующие категорию сатирического гротеска, укрепленного абсурдом. Кроме того, в этой повести находим изобилие иронических афоризмов, деградирующих персонажей, в первую очередь тех, кто их произносит, но нередко используемых и в функции определителей явлений глобальных или вечных. Например, фальшивый демократизм диктатора Рыка разоблачают его на первый взгляд остроумные фразы о сущности демократии, России и народа: «Демократия, это разновидность полового извращения»; «Народу, у которого соборность в крови, партии не нужны»; «Россия, такая страна, где без самодержавия не разберешься» и т. п.

Автором вводятся также многозначные фамилии и прозвища, смешные абревиатуры (напр., «помнацбес» - помощник Избавителя Отечества по национальной безопасности), нередко создаваемые как пародия сокращений, распространенных в языке советской эпохи, и пародийные отсылки к разным текстам. Ключевое в содержании заглавное слово «демгородок» вписывается в традицию щедринской, замятинской и оруэловской сатиры, так как ему придан смысл прямо противоположный по отношению к буквальному, что усиливают слова, производные от него, напр., «демократизаторы» - дубинки, которыми снабжены солдаты, стерегущие изолянтов.

Поляков в своих поисках, аналогично как и постмодернисты, к которым иногда относят и его, тяготеет не только к классической (Гоголь, Щедрин, Булгаков), но и к массовой литературе, заимствуя из нее то, что является в какой-то мере гарантией популярности. Демгородок это пример синтеза разнообразных жанровых форм, так как политически-социальная проблематика уживается в нем с моделью сенсационной литературы, точнее шпионского детектива, но и любовного романа, и то с романтической концепцией любви. Примерно в половине текста читатель узнает, что никто из героев не является тем, за кого выдавал себя: влюбленный ассенизатор Курылев давно завербован в спецслужбы и выполняет спецзадание, сержант Хузин оказывается главой борющейся за власть оппозиционной партии и т.д. Шпионская интрига, вездесущность и осведомленность сотрудников внутренних служб обогащают и усиливают сатирическую экспрессию, а любовный сюжет с трагическим окончанием расширяет эмоциональный пласт изображаемого, соединяя временное и индивидуальное с универсальным. 
Очередное сатирическое произведение Полякова - роман Козленок в молоке переносит читательское внимание из области политики на литературную и окололитературную среду, на современных властелинов умов и диктаторов эстетических вкусов, т. е. на тех, от кого зависит, что появится на книжном рынке, кого из литераторов провозгласят гением, а кого уничтожат после дебюта. Как основа замысловатой интриги использован «бродячий» сюжет, выступающий уже, напр., у Валентина Катаева (комедия Случай с гением) и в массовой культуре, сюжет о временном возвышении ничтожества. Романным автором упомянутой затеи является главный герой-повествователь, у которого нет ни имени, ни фамилии. Это умный, эрудированный, находчивый, но не талантливый писатель, которому удалось напечатать лишь один роман из серии «История фабрик и заводов» и окказиональные графоманские стихи. Именно с его точки зрения оценивается текучий литературный процесс, механизмы человеческого поведения в писательской среде и отношения к ценностям в переходные эпохи. Герой Козленка гораздо злее Гуманкова из Парижской лбюви.., поэтому повествование в романе насыщено иронией, очень часто переходящей в сарказм. Уничижительные оценки, базирующие чаще всего на издевательских метафорах, распространяются и на жизнь в целом («мир стоит на трех огромных свиньях, грязных, смердящих и прожорливых» [Поляков, Козленок в молоке, 5 , online] и на литературу и литераторов. Сартр для героя является «тошнотворным», лауреаты нобелевской или букеровской премий графоманами. Для убедительности своей характеристики Поляков не щадит в глазах читателя, как можно предполагать, именно ради игры и повышения занимательности произведения, и самого себя, создав несколькими штрихами свой иронический автопортрет эпизодического персонажа (своеобразная «материализация» отчуждения от себя самого), наделив его рядом отвратительных черт. Читаем в повести:

(...) вслед за секретарем писательского парткома «семенил, озираясь бессмысленной комсомольской улыбкой, кудрявый юноша с ранним, но уже вполне обвисшим брюшком - лидер писательского комсомола, насчитывавшего в своих рядах четырех членов - больше взять было негде, так как средний возраст члена Союза в ту пору превышал шестьдесят восемь лет»; «Кто мог тогда подумать, что, воспользовавшись начатыми мной переменами, этот пузатый мерзавец через несколько месяцев достанет из стола и опубликует скандальную повестушку «ЧП районного масштаба» и не оставит на комсомоле, вскормившем его своей грудью, живого места!» (Козленок..., с. 131). 
Как видим, автор смеется и над своей внешностью, и над фрагментом биографии, и над оценкой своей (без)нравственности, но зато вводит вполне лестную оценку одной из своих книг, используя на этот раз «иронию наоборот», т. е. критику героя-повествователя в функции похвалы.

Характеристику столичной литературной жизни в романе дополняют информации о функционировании правления Союза писателей, профсоюзного ресторана (воскрешение атмосферы Дома Грибоедова из булгаковского Macmepa u Mapгapumbl) и издательств. Читатель узнает, что решения о публикации новых произведений принимаются редакторами совершенно необъективно. Иногда могут помочь обстоятельства, к литературе отношения не имеющие, напр., отдельная квартира, которую можно предоставить для любовных свиданий влиятельным людям из литературного бизнеса, романы с «литературными бабушками», т. е. авторитетными писательницами пожилого возраста, иногда сотрудничество с КГБ или деньги, вручаемые его агентам. В общем, изображенная в романе литературная среда состоит из бесталанных карьеристов, пьяниц, развратников и развратниц, завистливых и мстительных чудовищ. Герой убежден, что русская «писательская действительность изобилует случаями, когда слава выбирает и возносит на своих перепончатых крыльях таких умственных заморышей, что хочется плакать» (с. 40). Именно такая оценка литературных дел с точки зрения человека, мечтающего быть не «бумагомарателем», a «вседержителем, придумывающим живых людей» (с. 39) стала импульсом к замыслу вывести в литературные гении мало грамотного парня, который самостоятельно не написал ни строчки, и таким образом свести счеты за собственные неудачи. При помощи тщательно продуманного имиджа (авторская дань силе publice relation) и словаря в неполных 30 слов (перекличка с известным приемом Ильфа и Петрова в концепции их людоедки Эллочки), в состав которого вошли, м.п., многозначные фразы типа «вестимо», «амбивалентно», «скорее да, чем нет» и наоборот и сентенция «не вари козленка в молоке матери его», фальшивых комплиментов и маленьких интриг мистификация сработала и был создан забавный фантом оригинального писателя «из народной гущи».

Кроме подробных описаний явлений, сатирическую нагрузку несет динамическое действие, изобилующее в комические ситуации и неожиданные повороты. Возвышение профана в гении оказалось возможным прежде всего потому, что ни редакторы издательств, ни признанные в данное время писательские авторитеты, ни чиновники из Союза писа- 
телей, которые распространяли суждения о гениальности романа Акашина не только его не читали, но даже не открыли папку, в которой вместо текста хранились листы чистой бумаги. Но когда, наконец, в Америке наступило разоблачение и компрометация авторитетов, нелепую ситуацию попытался спасти один из обманутых критиков, продажный Любин-Любченко, «теоретик авангарда и практик андеграунда», придумав на ходу теорию «табулизма» как нового творческого метода. В теории подчеркивалось, что чистая страница это шифр для «выхода сознания в надсознание - к астральным сгусткам информационной энергии, где безусловно есть и сочиненный, но не записанный роман» (с. 165).

Кроме наплевательского отношения к обязанностям по работе среди работников сектора культуры, корыстности и эгоизма (сатирические темы из числа вечных) Поляковым высмеиваются и более сложные злободневные явления, прежде всего беспомощность настоящих эстетических и этических ценностей в столкновении с псевдоценностями в мире лжи, обмана, стремлений к комфорту, манипулирование общественным мнением, вплоть до утверждения в рекламах и публикациях парадоксального смысла [Большакова 2014, 177].

Ради создания сатирической образности Поляковым используются и широко распространенные в современной прозе решения, кроме уже сигнализированных сближений с попкультурой также возможности интертекстуальности. Писатель на разных уровнях конструкции произведений ведет свой диалог с классикой, с советской и постсоветской литературой, вводя аллюзии и намеки, припоминающие известных персонажей и сцены, обыгрывая цитаты, пародируя литературоведческие теории, в т.ч. погоню за новаторством как самоцель и т.п. Например, в Козленке читаем и о том, что представительницы московской богемы стремятся «переплавлять оргазм в поэзию», что теоретики создают нелепые программы типа «табулизм» или «контекстуализм» (его основа это утверждение «каков текст - таков контекст»), встречаем травести известных заглавий, напр., горьковское « $C$ кем вbl, мастера культуры?» - у Полякова «С кем вы, подмастерья культуры?» (с. 49) получает явно отрицательный аксиологический оттенок, а «Бостон - город хлебный»- иронически насмешливый и мстительный.

Еще один сатирообразующий прием, на который стоит обратит внимание, это активизация традиционных литературных кратких форм, в первую очередь, «эпиграммушечек», которые сочиняет главный герой, напр.: «Если сидишь над романом, пупея, // Это уже не 
роман - эпопея» (с. 49), которые обильно цитируются в тексте, рядом с графоманскими стихами и фрагментами прозы эпигонских или конъюнктюрных авторов. Такие «авто-цитации» в данном случае выступают в функции прямой речи, т. е. сатирической самохарактеристики персонажей.

В произведениях о современности Поляков любит эпилоги со своеобразным happy end-oм, показывающим, каким образом политические перемены влияют на судьбу героев, т. е. на «мутации гомосоветикуса» [Большакова 2009, online], в том числе временные упадки партфункционеров и рождение новых сильных мира сего, новых властелинов жизни. В проекции судеб в постсоветское время и в Парижской любви..., и в Козленке в молоке мечты о справедливости уступают силе обстоятельств, натиску зла. Хотя карьеристы в роде Горынина отправлены в отставку, их место занимают те, кого можно считать жертвами прежней системы (обходчик Гера), но они ничуть не лучше прежних. Союз писателей и вообще государство перестали быть «гигантской кассой взаимопомощи», но в литературе мало что изменилось - по-прежнему ощущается спрос на услуги умеющих подхалимничать - при новом строе главный герой пишет «эпиграммушечки» то для диктаторов из бывших республик, то для «новых» русских. Хорошее по-прежнему перемешивается с плохим, человеческие судьбы остаются непредвиденными.

В следующих своих произведениях, напр., Замьлслил я побег (1999), Грибной иарь (2005), Гипсовьий трубач (2012) и др., посвященных исследованию эпохи слома прежней системы и утверждения новых, не всегда лучше, чем старые, форм жизни, Поляков применяет богатый арсенал эпических, лирических и публицистических (философские раздумья) способов изображения, заботясь при этом о занимательности своих текстов (детективные интриги). Писатель использует в этих произведениях и возможности сатирической типизации, но, как и у многих других современных писателей сатира выполняет в них незначительную роль. Сам автор считает, что с обретением свободы сатира утратила свой прежний статус воспитательницы дум, так как сатирическое мироощущение и в писателе, и в читателе сильнее развито в эпоху несвободы [Поляков 2012, онлине], с чем однако трудно согласиться, так как новая действительность несет с собой не меньше отвратительного и абсурдного, как в социальной, так и аксиологической сфере, чем предыдущие эпохи, и современные национальные литературы ищут способы отражения и осмысления этих явлений. Конечно, меняется сущность и статус смешного и вслед за тем сатирического. 
Очередной, после «гомосоветикуса» сатирический герой русской литературы это «новый» русский.

Поляков обязан предшественникам довольно многим, прежде всего аналогичными темами, персонажами и ситуциями. Для изображения новых реалий он соединяет явления противоположные, напр., лиризм и трагизм, высокую и массовую культуру (сенсационные сюжеты), обильно использует анектоды и авторские афоризмы, благодаря чему он в некоторой степени обогатил возможности сатирической типизации.

\section{Литература}

Большакова А., 2014, В. Распутин и современный литературный прочесс, [в:] Творчество Валентина Распутина. Ответьи и вопросы, ред. И. Плеханова, Иркутск.

Большакова А., Время и временщики в мире Юрия Полякова, [online], www. zpu_yornal.ru/e-zpu/2009/5/bolshakova [10.09.2014].

Бондаренко В., 2001, Одинокий беглеи на длиннье дистанции, „Завтра”, 3 декабря, [online], zavtra.ru./content/view/2001-12-046 [15.09.2014].

Jankowski A., 1998, O satyrycznej powieści Jurija Polakowa „Paryska miłość Kosti Gumankowa”, [w:] Satyra w literaturach wschodniostowianskich, Białystok, t. 3 , s. $182-188$.

Курицын В., 1994, Феномен Юрия Полякова, [в:] Ю. Поляков, Избранное, Санкт-Петербург, т. 1, с. 488-505.

Поляков Ю., 2008, Демгородок, Москва, [online], http://www.litres.ru/pages/bib lio_book/?art.=122694 [10.09.2014].

Поляков Ю., интервью А. Каскову, [online], www.ks.gazeta.ru/index.php/soby tia3/643/ [10.09.2014].

Поляков Ю., 2005, Гротесковый реализм Юрия Полякова, „Вятский край”, 8 ноября, интервью, [online], www.vk-smi.ru/2005/novtm05/wknovo5005 03.htm [16.09.2014].

Поляков Ю., 2008, Козленок в молоке, Москва, [online], http://www.litres.ru/ pages/biblio_book/?art. $=122876$ [18.09.2014].

Поляков Ю., 2012, Недовольство людей растет, „Московский комсомолец”, 6 декабря, [online], polyakov./lgz.ru/news/81.php [16.09.2014].

Поляков Ю., Парижская любовь Кости Гуманкова, [online], www.newlibrary.ru /author/poliakjv_yrii.html [16.09.2014].

Румянцев, В., Поляков Юрий Михайлович, [online], http://www.za-libr.ru/Per sons/000/Src/0010/84b8df74.shtml [15.10.2014].

Supa W., 2002, W kręgu pojęć „satyra” $i$ „groteska”, [w:] Satyra w literaturach wschodniosłowianskich, Białystok, t. V. 
THE SATIRE OF J. POLAKOV

IN THE CONTEXT OF RUSSIAN CLASSICAL SATIRE ACHIEVEMENTS

\author{
S U M M A R Y
}

The article presents the analysis of the satirical works of J. Polakov: Парижская любовь Кости Гуманкова, Демгородок, Козлёнок в молоке in which the author laughs at the Soviet and the post-Soviet reality, especially pseudodemocracy and moral corruption in the literary circles. Polakov refers to achievements of the classical satire and in some way expands the possibilities of satirical depiction by using some solutions from the popular literature (anecdotes, sensational and romance themes). 